\title{
Anti-Ulcer Activity of Sacrocephalus Latifolius (Sm.) Bruce Leaf Methanol Extract on Absolute Ethanol-Induced Gastric Ulcer in Swiss Albino Rats
}

\author{
Ukwubile Cletus $\mathbf{A}^{\mathbf{1}}$, Samagoro Cynthia $\mathbf{T}^{\mathbf{2}}$ \\ ${ }^{I}$ Department of Science Laboratory Technology, Biology Unit, Federal Polytechnic Bali, Nigeria. \\ ${ }^{2}$ Department of Pharmacognosy, Gombe State University, Gombe, Nigeria.
}

*Corresponding Author: Ukwubile Cletus A, Department of Science Laboratory Technology, Biology Unit, Federal Polytechnic Bali, Nigeria.

\begin{abstract}
Sacrocephalus latifolius is used in folk medicine for treatment of menstrual pain, stomach disorders; including gastric ulcer. The methanol extract of Sacrocephalus latifolius was evaluated for antiulcer activity in twenty-five Swiss albino rats divided into five groups of five rats per group. Various doses 100,200 and $400 \mathrm{mg} / \mathrm{Kg}$ of leaf extracts were administered orally to the animals in groups II -V while Omeprazole (B.P) $20 \mathrm{mg}$ (Standard drug) was used as positive control in group I animals and normal saline $10 \mathrm{~mL}$ was used in the negative control group II. Stomach was opened along the greater curvature then; ulceration index was determined by examining the inner lining of stomach. Results showed that the rate of ulceration decreases in area of stomach affected with increased doses. Rats in group V with dose $400 \mathrm{mg} / \mathrm{Kg}$ of leaf extract showed the most reduced affected area with $1.2 \pm 0.3 \mathrm{~b}$ and $76 \%$ inhibition of ulceration while group II with dose $10 \mathrm{~mL}$ normal saline (negative control) has the highest rate of ulceration of $8.0 \pm 0.3 \mathrm{~b}$. The study showed that Sacrocephalus latifolius leaf decreased the area of ulceration in the stomach of rats in dose-dependent fashion, thus justifies its used in traditional medicine in the treatment of gastric ulcer.
\end{abstract}

Keywords: Anti-Ulcer, Sacrocephalus latifolius, Omeprazole, Gastric ulcer, Dose-dependent

\section{INTRODUCTION}

The term ulcer refers to the discontinuity or break in a bodily membrane that impedes the organ of that membrane form continuing its normal function. In medical pathology ulcer is the branch of the continuity of skin, epithelium or mucous membrane caused by sloughing out of inflamed necrotic tissue. The various types ulcer are: esophagus (ulcer that develop inside the esophagus), duodenal ulcer (ulcer that develop in the upper section of the small intestine, called the duodenum), and Gastric ulcer (ulcer that develop inside the stomach).

Gastric ulcer is also known as peptic ulcer is a localized area of erosion in the stomach lining, resulting in abdominal pain; possible bleeding caused by a break or bleaching in normal tissue that lines the stomach walls, while other gastric ulcer is as a result of infection associated with a Gramnegative, 4-6 flagellated micro-aerophilic bacterium Helicobacter pylori (previously known as Campylobacter pylori); a member of the Family Helicobacteraceae [1].

The plant Sacrocephalus latifolius is a member of the Rubiaceace Family. It is locally called "Tatashiya" in Hausa "Ubuluinu"in Igbo and "Egbsi" in Yoruba language. The plant is commonly called "Pin Cushion" tree and majorly found in the tropics of Africa and Asia [2]. It grows to an altitude of $200 \mathrm{~m}$ in Savannah woodland of west and central Africa countries like Nigeria, Ghana, Uganda, etc. It has been used in traditional medicine for treating fever, helminthes infections, diarrhea and menstrual pains. Chemically, the plant leaf extract contains, mainly glycosides especially flavonoids as well as alkaloids [3]. The fruit is said to resemble a strawberry in taste and texture, and is about $8 \mathrm{~cm}$ in diameter. Flower heads are cooked and eaten as a vegetable while the fruits are eaten as a cure for coughs [4]. The bark and roots of plant contain more than $1 \%$ of an opioid that is clinically identical to the anesthetic drug tramadol [5]. This present study was carried out in order to determine the anti-ulcer activity of methanol leaf extract of Sacrocephalus latifolius in absolute ethanol-induced gastric ulcer in Swiss albino rats. 


\section{Materials AND Methods}

\subsection{Materials}

The materials used in this research include: Sacrocephalus latifolius leaf extract, twenty-five (25) Swiss albino rats, methanol (analytical grade), Omerazole B.P, Soxhlet apparatus, rotary evaporator, 1 $\mathrm{mL}$ syringe and needle, desiccator, absolute ethanol [100\% (v/v)], among others.

\subsection{Methods}

\subsubsection{Collection and identification of plant}

Fresh leaves of Sacrocephalus latifolius were collected in the morning hours from Sabon Dali District of Bali Local Government Area, Taraba State, and were identified by a taxonomist in Biology Unit of the Department of Science Laboratory Technology. A plant press was made and deposited in the herbarium of Biology unit of Science Laboratory Technology, Department, and Federal Polytechnic Bali Taraba State with Voucher number of RUB001.

\subsubsection{Preparation and extraction of plant materials}

The leaf of Sacrocephalus latifolius were air dried at room temperature at $25{ }^{\circ} \mathrm{C}$ for two weeks and ground into powder using electronic blender. The ground powder was weighed on a scale balance and defatted in $900 \mathrm{~mL}$ pet-ether before been extracted with $1250 \mathrm{~mL}$ methanol (Sigma Aldrich) in a Soxhlet apparatus for 8 hours at room temperature. The extract was then filtered using a Whatman No 1 filter paper. The filtrate was concentrated in vacuo at room temperature using rotary evaporator. Final percentage yield of the methanol leaf extract was calculated and then stored in desiccator for further use.

\subsubsection{Animal grouping}

Twenty-five Swiss albino rats were purchased on demand from the animal house of the Department of Pharmacology, University of Jos, Nigeria. They were housed for one week under a $24 \mathrm{~h} \mathrm{light} \mathrm{/} \mathrm{dark}$ cycle and a temperature of $25{ }^{\circ} \mathrm{C} \pm 2{ }^{\circ} \mathrm{C}$ and humidity $60.0 \pm 5 \%$ controlled room and freely fed standard laboratory with water ad libitum. The animal was divided into five groups of five rats per group.

\subsubsection{Gastric ulcer induction by absolute ethanol $100 \%(\mathrm{v} / \mathrm{v})$}

The animal was fasted for $24 \mathrm{~h}$ period to the experiment [6]. Groups I and II received vehicle $20 \mathrm{mg}$ and $10 \mathrm{~mL}$ Omeprazole and normal saline respectively orally. Group III received an oral dose of 100 $\mathrm{mg} / \mathrm{kg}$ SLME while groups IV and V received S. latifolius methanol extract (SLME) at doses of 200 and $400 \mathrm{mg} / \mathrm{kg}$ as pre-treatment. 1hour after pre-treatment, absolute ethanol was orally administered to the groups in order to induce gastric ulcers. One hour later, the rats were euthanized, and their stomachs were dissected.

\subsubsection{Ulceration studies of stomach walls}

The stomachs were collected and fixed in $10 \%$ formalin dehydrated in graduated ethanol (50-100\%) cleared in chloral hydrate, and embedded in paraffin, section $4-5 \mu \mathrm{m}$ thick were prepared and stained with haematoxylin and eosin (H-E) dyes, and examined for area of ulceration under the microscope using 100x magnification of Olympus biological microscope. The affected ulcer areas where measured using the calibrated scales on the microscope. Percentage ulceration inhibition was calculated from the formula:

[Ulcer area in positive control group - Ulcer area treated groups /positive control] x 100.

\subsection{Statistical Analysis}

All values are reported as the mean \pm S.E.M and were analyzed by one-way analysis of variance (ANOVA) for comparison of significance difference between treated and untreated groups. The differences between means were considered statistically significant at $\mathrm{p} \leq 0.05$.

\section{RESULTS AND DISCUSSION}

Absolute ethanol-induced writhing test is commonly used as an experimental model in animals for gastric ulcer evaluation. This method is very sensitive and able to detect ulcer at dose that may appear 
to be inactive in most cases. Certain anti-ulcer drugs have been reported to increase the amount of gastric mucus secretion in the gastric mucosa. In this present study, S. latifolius leaf methanol extract (SLME) significantly increased the gastric mucus content in rats absolute ethanol-induced ulcer which indicate that the gastro-protective effect of Sacrocephalus latifolius was mediated by the preservation of gastric wall mucus [7-9].

The plant extract displayed dose-dependent reduction ulcer areas in the animal groups. This result was comparable to the effect seen in group I (positive control) administered with $20 \mathrm{mg}$ Omeprazole orally for four weeks with affected ulcer area of $5.0 \pm 0.02 \mathrm{a} \mathrm{mm} \mathrm{mm}^{2}$ as compared to those in group $\mathrm{V}$ with $1.2 \pm 0.3 \mathrm{~b} \mathrm{~mm}^{2}$ (Table 1 and Figure 1a-d) ' This further showed that the higher the dose of the plant extract, the lower the area of stomach affected and vice versa. Ethanol induced gastric ulceration may be occurred due to stasis in gastric blood flow which contributes to the development of the haemorrhage and necrotic tissue injuries. Alcohol has ability to penetrate the gastric mucosa and causing the cellular damage which increases the permeability to sodium and water. In other hand, the accumulation of intracellular calcium causes the pathogenesis of gastric injury that leads to cell death and exfoliation of surface epithelium [10-11]. The present study found that the SLME significantly reduced ethanol induced ulcer by cyto-protective action through antioxidant effect. In this present study, the plant extract prevents the ulcer may be by anti-secretory and cyto-protective property.

Ethanol is responsible for disturbances in gastric secretion, damage to the mucosa, alterations in the permeability, gastric mucus depletion and free radical production. The generation of free radicals was produced by continuous release of superoxide anion and hydroperoxy free radicals during metabolism of ethanol [12-15].

Table1. Anti-Ulcer activity of Sacrocephalus latifolius leaf methanol extract

\begin{tabular}{|l|l|l|}
\hline \multicolumn{1}{|c|}{ Animal (g) } & \multicolumn{1}{c|}{ Ulcer area $\left.\mathbf{( m m}^{2}\right)$ after $\mathbf{~ h}$} & \%Inhibition \\
\hline Group I 20 mg Omeprazole & $5.0 \pm 0.02 \mathrm{a}$ & - \\
\hline Group II 10mg normal saline & $8.0 \pm 0.3 \mathrm{~b}$ & 60 \\
\hline Group III 100mg/kg SLME & $2.3 \pm 0.2 \mathrm{a}$ & 54 \\
\hline Group IV 200mg/kg SLME & $1.8 \pm 0.2 \mathrm{a}$ & 64 \\
\hline Group V 400mg/kg SLME & $1.2 \pm 0.3 \mathrm{~b}$ & 76 \\
\hline
\end{tabular}

Results are mean \pm S.E.M, $n=5$, number followed by the same alphabets are statistically significant at $p \leq 0.05$ (one-way ANOVA), SLME (Sacrocephalus latifolius extract).

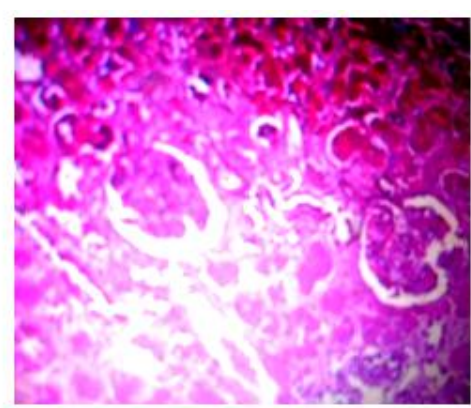

a. H\& $\mathbf{E}$ stain positive control

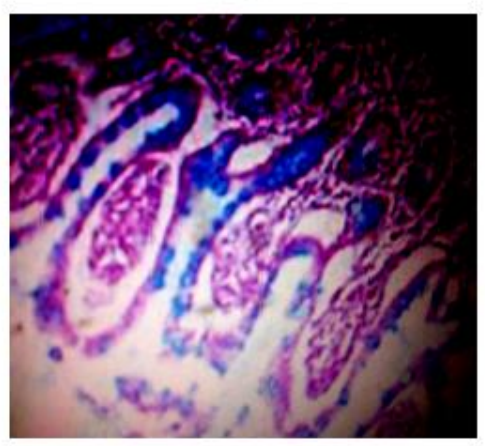

c. H\& E stain of treated groups

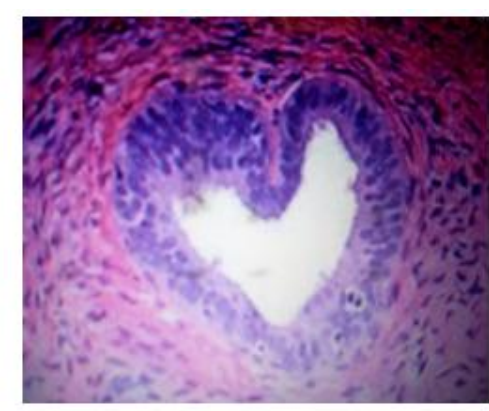

b. $\mathrm{H} \& \mathrm{E}$ stain of negative control

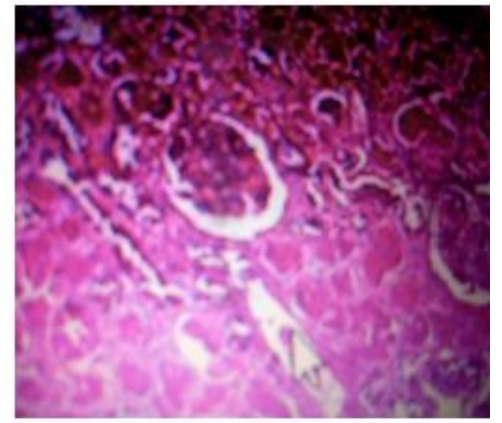

d. H \& E stain of treated groups

Figure1: $H \&$ E stains of stomach wall to determine ulceration areas $100 x$ 


\section{Conclusion}

The results of the study indicate that Sacrocephalus latifolius leaf methanol extract have greater efficacy against gastric ulcer which supports the traditional claims for its use as anti-ulcer agent in folklore medicine. This plant thus, served as a promising material for the discovery of ulcer drugs in orthodox medicine.

\section{ACKNOWLEDGEMENT}

The authors are thankful to Mr Livinus Tam of Sancta Maria Clinic Laboratory Bali (FhI USAID affiliate) who helped in providing necessary facilities to carry out this present research work.

\section{REFERENCES}

[1] Abdulla, M.A, Ahmed, K.A.A, Albayaty, F.H, Masood, D.Y (2010).Gastro protective effect of Phyllanthus nururi leaf extract against ethanol-induced gastric mucosal injury in rats. African journal of Pharmacy and Pharmacology, 4: 226-236.

[2] Abbiw, D. (1990). Useful p lants of Ghana. Intermediate Technology Publications and the Royal Botanical Gardens, Kew.

[3] Balogun, M. E, Nwachukwu, D., Diwe, P.E, Falwiyo, M.H (2014). Gastric acid anti-secretory effects of aqueous leaf extract of Sacrocephalus latifolus (Rubiaceace) in rats. The Journal of pytopharmacology, 3(6): 389-394.

[4] Madubunyi, I.I. (1995). Anti-hepatotoxic and trypanocidal activities of the ethanolic extract of Nauclea latifolia root bark. Journal of Herbs, Spices and Medicinal Plants, 3(2): 23-35.

[5] Sourabie, S., Kabore, Z...I and Guissou, I.P. (1994). Study comparing the antibacterial of aqueous alcoholic extracts of the active constituents of Holarrhena floribunda (G. Don) Dur et Schinz and Nauclea latifolia Sm. Medecine d'Afrique Noire,

[6] 41(3): 181-185.

[7] Steentoft, M. (1988). Flowering plants in West Africa. Cambridge University Press, Cambridge.

[8] Akubae, P. Mittal, G.C, (1982). Clinical evaluation of a traditional herbal practice in Nigeria. A preliminary Report. Journals of ethno pharmacology, 6(3):355-359.

[9] Duk, J.A (2008.) Ethno botanical uses of Sacrocephalus latifolus. Phytochemical and ethno botanical databases. Available from http://www.bartleby.com (Cast accessed on oct15. (2008).

[10] Iwu, M.M, (1993). Handbook of African medicinal plant C.R.C press, Florida, Pp.64

[11] Dwivedi, V., Chander, B.S., Yadav, N.H. (2014). Evaluation of anti-ulcer activity of Clitorea ternatea Leaves (Linn) extract in Wistar rats. Indian Journal of Research in Pharmacy and Biotechnology. 3:122529.

[12] Ukwubile, C.A., Agu, M.O, Agabila,J. E.(2015) Toxicity and Phytochemical screening of M. capitatum leaf extract, International Journal of Biology and applications; 3(2): 58- 62.

[13] Jude, E.O, Paul, A. (2009). Antiulcer and Anticonvulsant Activity of Croton Zambesicus. Journal of Pharm Science, 22:384-90. [PubMed]

[14] Mahmood, A., .Mariod, A.A, AI-B, Ayaty, F, Abdel-wahab S. (2010). Antiulcerogenic activity of Cynura procumbens leaf extract against experimental Ly-induces gastric lesions in rats, J med plant RCS1:685891.

[15] Asuzu, I.U. and Njoku, C.J. (1996). The anthelmintic effect of Alstonia boonei bark and Nauclea latifolia leaf aqueous extracts on Trichostrongylus infective larvae. Fitoterapia, 67(3): 220-222.

[16] Duez, P. et al. (1994). Comparison of HPTLC-fluorodensitometry and HPLC for the assay of strictosamide in the leaves, root and stem bark of Nauclea latifolia. Journal of Planar Chromatography, 7(1): 5-9.

Citation: A. U. Cletus et al., " Anti-Ulcer Activity of Sacrocephalus Latifolius (Sm.) Bruce Leaf Methanol Extract on Absolute Ethanol-Induced Gastric Ulcer in Swiss Albino Rats", ARC Journal of Pharmaceutical Sciences (AJPS), vol. 3, no. 3, p. 5-8, 2017. http://dx.doi.org/10.20431/2455-1538.0303002

Copyright: () 2017 Authors. This is an open-access article distributed under the terms of the Creative Commons Attribution License, which permits unrestricted use, distribution, and reproduction in any medium, provided the original author and source are credited. 